Dicle University Journal of Engineering (DUJE)

web: http://dergipark.gov.tr/dumf

Araştırma Makalesi / Research Article

\title{
Geoteknik Mühendisliğinde Açık Kaynaklı Yazılım Geliştirme Araçlarının Kullanımı: Hidrometre Deneyi Örneği
}

\section{Use Of Open-Source Software Development Tools In Geotechnical Engineering: Example Of Hydrometer Test}

\author{
Muhammet Dingil $^{1 *}$, Yakup Türedi², Murat Örnek ${ }^{3}$ \\ ${ }^{1}$ İskenderun Teknik Üniversitesi, İnşaat Mühendisliği Bölümü, Hatay, ORCID: 0000-0002-8681-478X, muhammetdingil.mfbe19@iste.edu.tr \\ 2 İskenderun Teknik Üniversitesi, İnşaat Mühendisliği Bölümü, Hatay, ORCID: 0000-0001-9197-5214, yakup.turedi@ iste.edu.tr \\ ${ }^{3}$ İskenderun Teknik Üniversitesi, İnşaat Mühendisliği Bölümü, Hatay, ORCID: 0000-0002-0809-2531, murat.ornek@ iste.edu.tr
}

\begin{tabular}{|c|c|}
\hline \multicolumn{2}{|c|}{ MAKALE BİLGİLERİ } \\
\hline \multicolumn{2}{|c|}{ Makale geçmişi: } \\
\hline Geliş: & 18 Haziran 2020 \\
\hline Düzeltme: & 15 Temmuz 2020 \\
\hline Kabul: & 17 Temmuz 2020 \\
\hline \multicolumn{2}{|c|}{ Anahtar kelimeler: } \\
\hline \multicolumn{2}{|c|}{$\begin{array}{l}\text { açık kaynak, geoteknik yazılım, } \\
\text { hidrometre deneyi, yazılım } \\
\text { geliştirme, internet tabanlı } \\
\text { uygulama }\end{array}$} \\
\hline
\end{tabular}

\begin{abstract}
ÖZET
Geoteknik mühendisliğinde, araştırma konuları kapsamında başvurulan arazi ve laboratuvar deneylerinin çözümlenmesinde, yazılımlar yaygın olarak kullanılmaktadır. Arazi ve laboratuvar deneylerinin çeşitliliği, araştırma ölçeğine göre çok sayıda deney verisinin olabilmesi ve çözümleme sonucu bulgulara bağlı olarak bazı görsel ögeler sunma gerekliliği; ticari amaçlı yazılım geliştirme hizmetlerinin ve kapalı kaynak uygulamaların çoğul hale gelmesine neden olmustur. Bu çalıșmada, geoteknik mühendisliğinde zemin endeks özelliklerini tanımlamada kullanılan laboratuvar deneylerinden biri olan hidrometre deneyinin; veri alma, değerlendirme ve çözümleme süreçleri, birtakım bütünleşik açık kaynaklı yazılım geliştirme araçlarında kodlanarak, internet tabanlı bir uygulama geliştirilmiştir. Bilimsel yayınlardan derlenen hidrometre deneyi verilerinin sanal çözümlemesi gerçekleştirilerek, yazılımın hesap doğrulaması sağlanmıștır. Yazılımdaki girdi veriler, akış yolu adımları içerisinde çözümlenerek uluslararası standart esasına uygun çizelgeler ve grafikler olarak, internet tarayıcısı üzerinden kullanıcılara sunulmuştur. Sonuç olarak, mevcut ticari yazılımların yaygınlığına ve erişim yoğunluğuna karșı, açık kaynaklı yazılım geliștirme araçlarının, bu çalışmadan hareketle, geoteknik mühendisliği uygulama geliştirme alanında son derece kullanılabilir olduğu sonucuna varılmıştır.
\end{abstract}

Doi: $10.24012 /$ dumf. 754582

\begin{tabular}{ll}
\hline ARTICLE INFO & $\begin{array}{l}\text { ABSTRACT } \\
\text { Article history: }\end{array}$ \\
$\begin{array}{l}\text { Received: } 18 \text { June } 2020 \\
\text { Revised: } \quad 15 \text { July } 2020\end{array}$ & $\begin{array}{l}\text { within the scope of research topics. The diversity of the in-situ and laboratory experiments, the availability of a } \\
\text { large number of experimental data according to the research scale, and the necessity to present some visual } \\
\text { elements depending on the findings as a result of analysis; has led to the plurality of commercial software } \\
\text { development services and closed source applications. In this study, a hydrometer experiment, which is one of the } \\
\text { laboratory experiments used in defining soil index properties in geotechnical engineering; a web-based application } \\
\text { has been developed by coding data acquisition, evaluation, and analysis processes in a number of integrated open- } \\
\text { source software development tools. A virtual analysis of hydrometer experiment data compiled from scientific } \\
\text { publications was carried out and account verification of the software was provided. The input data in the software } \\
\text { are analyzed within the algorithm steps and presented to the users via the internet browser as charts and tables in } \\
\text { accordance with the international standard. As a result, it has been concluded that open-source software } \\
\text { development tools are highly available in the field of geotechnical engineering application development, based on } \\
\text { the prevalence and access density of existing commercial software. }\end{array}$ \\
$\begin{array}{l}\text { open-source, geotechnical } \\
\text { software, hydrometer test, } \\
\text { software development, } \\
\text { web-based application }\end{array}$ &
\end{tabular}

* Sorumlu yazar / Correspondence

Muhammet DINGiL

$\triangle$ muhammetdingil.mfbe19@iste.edu.tr 


\section{Giriş}

Geoteknik mühendisliğinde, bir projenin tasarım ve uygulama aşamasında; mukavemet, sıkılık, endeks özellik, sınıflandırma gibi çeşitli zemin niceliklerini saptamak amaciyla birçok laboratuvar ve arazi deneyleri gerçekleștirilmektedir. Geoteknik mühendisliğinde laboratuvar ve arazi deneylerinin sağlıklı bir biçimde sonuçlandırılması için, numune alma ve yerleştirme yöntemi, kullanılan donanımların bakımı, deney yürütücüsü tecrübesi, en elverișli muhafaza koşullarının sağlanması gibi birçok etken bulunurken bu etkenlerden biri de deney verilerinin ilgili standart esasına uygun olarak çözümlenmesidir. Konu olan tasarım veya uygulama çalışmasına bağlı olarak, geoteknik deneylerin çeşitliliği, tekrar sayısı ve yineleme aralığı göz önüne alındığında; deneylerin değerlendirme adım sayısından bağımsız olarak, deney çözümlemeleri için bilgisayar imkânlarından yararlanmak büyük kazanç sağlamaktadır. Bu nedenle, günümüz şartlarında geoteknik mühendisliğinde, laboratuvar ve arazi deneylerinin veri saklama ve çözümleme amacıyla çeşitli özel amaçlı ticari yazılımlar ile elektronik çizelge yazılımları birçok kullanıcı tarafindan yaygin olarak tercih edilmektedir. Buna karşın, birçok mühendislik disiplininde, kullanıma sunulmuş ticari yazılımlar ve kapalı paket uygulamalar bulunmasına rağmen, açık kaynak yazılımlara doğru ciddi bir eğilim bulunmaktadır. Açık kaynak yazılımlara yönelimin temel sebebi; geçmiş yıllarda, var olan kod tabanının ihtiyaca göre yinelenip tekrar kullanımının mümkün olması iken son yıllarda, açık kaynak yazılım ürünlerinin birçok geliştiricinin dikkatli incelemesinden geçmiş ve hatalardan arındırılmış olmasının yaygın görüş olmasıdır [1]. Açık kaynak yazılımların; baştan sona uygulama işleyişine müdahale edebilme, herhangi bir ücret ve abonelik gerektirmeme, çok katılımlı geliştirme öykülerine uygun olma, yazılım amacına göre uluslararası ya da yerel sürümler şeklinde genişletilebilme gibi özgür lisans-birlikte geliştirme kapsamına girebilecek birçok öne çıkan özellikleri bulunmaktadır. Buna ek olarak, geoteknik mühendisliğinde açık kaynaklı donanım geliştirmeye yönelik, geçmiş yıllarda yapılmış bazı bilimsel çalışmalar ve donanım seçenekleri hâlihazırda bulunmaktır [2],[3]. Bu yüzden, açık kaynak yazılım geliştirme araçlarının da geoteknik mühendisliği çözümlemelerine yönelik uygulama geliștirme amacıyla kullanılabileceği düşünülmektedir. $\mathrm{Bu}$ çalışmada, geoteknik mühendisliği laboratuvar deneylerinden örnek olarak seçilen hidrometre deneyini, uluslararası standart esasları doğrultusunda çözümlemek amaciyla, tamamen açık kaynak yazılım geliştirme araçları kullanılarak, kullanıcı etkileșimli ve internet tabanlı bir uygulama tasarlanmıştır.

\section{Teori}

Hidrometre deneyi, çok küçük boyutlu daneciklerden oluşan zeminlerin (ince daneli), dane boyutunun belirlenmesi amaciyla gerçekleştirilen ve çözümleme yöntemi Stokes yasasına dayanan bir çöktürme analizidir [4]. Hidrometre deneyinde zemin daneleri; içi su dolu olan bir silindirde, yerçekimi ve zemin örneği kütlesinin etkisiyle çökmeye bırakılmaktadır. Hidrometre adı verilen silindirik donanımla, belli zaman dilimlerinde, danelerin çökme mesafesi ve zemin örneği-su karışımının yoğunluğu saptanmaktadır. Stokes ilkesine göre dane çapları Eşitlik 1'de açıklanmaktadır.

$$
D=\sqrt{\frac{18}{1} * \frac{n}{\gamma_{s}-\gamma_{w}} * \frac{L}{T}}
$$

$\mathrm{Bu}$ eşitliğe göre:

$D=$ eşdeğer küre çapı, $\mathrm{mm}$

$n=$ suyun akmazlığ 1 (viskozite), $\mathrm{g} / \mathrm{cm} . \mathrm{sn}$

$\gamma_{s}=$ danelerin birim hacim ağırlı̆

$\gamma_{w}=$ suyun birim hacim ağırlığ $1, \mathrm{~g} / \mathrm{cm}^{3}$

$L=$ danelerin çökme mesafesi, $\mathrm{cm}$

$T=$ çökme işleminin başlangıcından itibaren geçen zaman, sn olarak ifade edilmektedir.

Yazılım içerisinde öykülenen hidrometre deneyinde, esas alınan uluslararası standart; ASTM standardı olarak seçilmiştir [5],[6]. ASTM standardına göre, hidrometre donanımı 
kullanılarak yapılan çöktürme deneyi; dane boyutları 0.075 'mm'den küçük olan siltli ve killi zeminlerin dane çapı dağılımını belirlemek için yararlanılan ölçünlü bir yöntemdir [7]. ASTM standart esasına göre deneyin yürütülmesi için $151 \mathrm{H}$ ve $152 \mathrm{H}$ olmak üzere iki tip hidrometre tanımlanmıştır. Hidrometre deneyinde, kullanılan silindirik donanım üzerinden okunan asıl hidrometre okuma değerleri üzerinde; menüsküs çizgisi, sıcaklık etkisi ve dağıtma maddesi gibi çeşitli etkenler doğrultusunda okuma düzeltmeleri yapılması gerekmektedir. Suyun hidrometre sapında ve çöktürme silindiri duvarında yüzey gerilim kuvvetlerinden dolayı yukarı yönde bir miktar tırmanarak meydana getirdiği kavise menüsküs adı verilmektedir [4]. $\mathrm{Bu}$ nedenle, bahsedilen menüsküs etkisinden kaynaklanan bu kavisten dolayı; suyun düşey yönde kıvrıldığı noktada, yapılacak asıl okumanın suyun üst yüzeyi seviyesinden yapılması son derece önemlidir (Şekil 1).



Şekil 1. Assl hidrometre okuması ve düzeltilmiş okumanın yapılması [4]

As1l hidrometre okumasinda, uygulanacak düzeltme miktarı ASTM standart esasında yer alan deneysel yöntemlerle gerçekleştirilir [5]. Hidrometre deneyinde $20^{\circ} \mathrm{C}$ sicaklıktan farklı olarak ölçülen sıcaklık değerleri ve karşılık gelen hidrometre okumaları bir eksen takımı üzerine aktarılır. Eksen takımında temsil edilen noktalardan oluşan en iyi doğru yani regresyon doğrusu çizilir ve $20^{\circ} \mathrm{C}$ sıcaklıktan farklı olarak ölçülen sıcaklıklar için en uygun düzeltme okumaları elde edilmiş olur. Asıl hidrometre okumalarına menüsküs çizgisi düzeltmesi eklenir, sicaklık ve dağıtma maddesi nedenli düzeltmeler ise çıkarılır ve nihayetinde kalan yalın değerler, düzeltilmiş hidrometre okumaları olarak adlandırılır. Hidrometre deneyinde, asıl hidrometre okumaları üzerinde gerekli düzeltmeler yapıldıktan sonra, deneyin en önemli çözümleme adımı; dane çaplarının hesaplanmasıdır. Dane çapının hesaplanma yöntemi, Eşitlik 2'de yer alan denklemle açıklanmaktadır.

$$
D=K * \sqrt{\frac{L}{T}}
$$

$\mathrm{Bu}$ eşitliğe göre:

$D=$ dane çapı, $\mathrm{mm}$

$K=$ zemin örneğinin özgül ağırlığına ve karışımın sıcaklığına bağlı olarak değișen bir katsayı

$L=$ etkin derinlik, $\mathrm{cm}$

$T=$ deneyin başından hidrometre okuması yapılan ana dek geçen süre, $\mathrm{dk}$ olarak ifade edilmektedir [6].

Eşitlik 2'de yer alan $K$ değeri, hidrometre deneyi uygulanan zemin örneği karışımının sıcaklığına ve zemine ait boyutsuz özgül ağırlığa göre tespit edilen bir sabit katsayıdır. $K$ katsayı değerleri, ASTM standart esasında sicaklık ve özgül ağırlığa bağlı olarak hazırlanmış çizelgeler üzerinden okunabilmektedir [6]. Bu standart içerisinde yer alan bazı $K$ katsayı çarpanlarından bir kısmı Çizelge 1'de verilmiştir. Etkin derinlik $(L)$; hidrometrenin zemin örneği karışımının içerisine daldırılmadan önce, karışımın üst seviyesi ile hidrometre ağırlık merkezi arasında kalan düşey mesafe olarak adlandırılmaktadır [4]. Hidrometre deneyinde, deney öncesinde gerçekleștirilecek bir ölçümleme yoluyla etkin derinlik sınır koşulları hesaplanmalıdır. Ölçümleme işlemi ve bağıl olarak hesaplanan etkin derinlik değeri; deneyde yararlanılan çöktürme silindirine ve hidrometreye bağlı değerlerdir. $\mathrm{Bu}$ nedenle etkin derinliğin tespit edilebilmesi için, kullanılan hidrometre tipine 
Çizelge 1. Bazı sıcaklık ve özgül ağırlık değerlerine karşılık gelen bazı $K$ sabit katsayıları [6]

\begin{tabular}{cccccc}
\hline \multirow{2}{*}{ Sıcaklık } & \multicolumn{5}{c}{ Zemin danelerine ait özgül ă̆ırlık } \\
\cline { 2 - 6 } & 2.45 & 2.50 & 2.55 & 2.60 & 2.65 \\
\hline 16 & 0.001530 & 0.001505 & 0.001481 & 0.001457 & 0.001435 \\
17 & 0.001511 & 0.001486 & 0.001462 & 0.001439 & 0.001417 \\
18 & 0.001492 & 0.001467 & 0.001443 & 0.001421 & 0.001399 \\
19 & 0.001474 & 0.001449 & 0.001425 & 0.001403 & 0.001382 \\
20 & 0.001456 & 0.001431 & 0.001408 & 0.001386 & 0.001365 \\
21 & 0.001438 & 0.001414 & 0.001391 & 0.001369 & 0.001348 \\
22 & 0.001421 & 0.001397 & 0.001374 & 0.001353 & 0.001332 \\
23 & 0.001404 & 0.001381 & 0.001358 & 0.001337 & 0.001317 \\
24 & 0.001388 & 0.001365 & 0.001342 & 0.001321 & 0.001301 \\
25 & 0.001372 & 0.001349 & 0.001327 & 0.001306 & 0.001286 \\
26 & 0.001357 & 0.001334 & 0.001312 & 0.001291 & 0.001272 \\
27 & 0.001342 & 0.001319 & 0.001297 & 0.001277 & 0.001258 \\
28 & 0.001327 & 0.001304 & 0.001283 & 0.001264 & 0.001244 \\
29 & 0.001312 & 0.001290 & 0.001269 & 0.001249 & 0.001230 \\
30 & 0.001298 & 0.001276 & 0.001256 & 0.001236 & 0.001217 \\
\hline
\end{tabular}

göre, silindir enkesit alanı, hidrometre gövde uzunluğu, hidrometre hacmi dâhil olmak üzere bazı gerekli uzaklıklar ve boyutlar bilinmelidir (Şekil 2).

$$
L=L_{1}+\frac{1}{2} x\left(L_{2}-\frac{V_{B}}{A}\right)
$$

Bu eşitliğe göre:



Şekil 2. Hidrometre deneyi için $L$ etkin derinliğin tanımlanması [8]

Etkin derinlik değeri, Şekil 2'de yer alan kaynak ölçülere ve hidrometre tipine göre Eşitlik 3'te açıklanmaktadır.
$L=$ etkin derinlik, $\mathrm{cm}$

$L_{1}=$ hidrometre okuması ile hidrometrenin boyun kısmı arasında kalan uzaklık, cm

$L_{2}=$ hidrometre gövdesinin uzunluğu, $\mathrm{cm}$

$V_{B}=$ hidrometrenin hacmi, $\mathrm{cm}^{3}$

$A=$ çöktürme silindirinin en kesit alanı, $\mathrm{cm}^{2}$ olarak ifade edilmektedir.

ASTM standart hidrometre tipleri olan $151 \mathrm{H}$ ve $152 \mathrm{H}$ için $V_{B}, A$ ve $L_{2}$ değerleri ortak iken, her iki hidrometre tipine ait $L_{1}$ değerinin hesaplanabilmesi için ASTM standardı içerisinde ilk ve son ölçümler verilmiştir [6]. Çizelge 2'de yer alan standart hidrometre ölçüleri göz önüne alındığında; bir hidrometreye ait etkin derinliğin saptanabilmesi için Eşitlik 3'te yer alan değişkenlerin bilinen değerleri, Çizelge 2'den temin edilmektedir. $L_{1}$ değişkenine bağlı olan $L$ etkin derinlik ise Eşitlik 4'te açıklanmaktadır. 
Çizelge 2. ASTM hidrometre tiplerine göre standart hidrometre ölçüleri ve okuma-ölçüm değerleri [6]

\begin{tabular}{ccc}
\hline Değerler & ASTM 151H & ASTM 152H \\
\hline $\mathrm{L}_{1 \text { ilk }} / \mathrm{R}_{\mathrm{ilk}}$ & $10.5 \mathrm{~cm} / 1.000$ & $10.5 \mathrm{~cm} / 0 \mathrm{~g} /$ litre \\
$\mathrm{L}_{1 \text { son }} / \mathrm{R}_{\text {son }}$ & $2.3 \mathrm{~cm} / 1.031$ & $2.3 \mathrm{~cm} / 50 \mathrm{~g} /$ litre \\
$\mathrm{A}$ & $27.8 \mathrm{~cm}^{3}$ & $27.8 \mathrm{~cm}^{3}$ \\
$\mathrm{~V}_{\mathrm{B}}$ & $67.0 \mathrm{~cm}^{3}$ & $67.0 \mathrm{~cm}^{3}$ \\
$\mathrm{~L}_{2}$ & $14.0 \mathrm{~cm}$ & $14.0 \mathrm{~cm}$ \\
\hline
\end{tabular}

$L=L_{1}+5.795$

Çizelge 2'de yer alan her bir hidrometre tipi için $L_{\text {lilk }}$ ve $L_{1 s o n}$ kullanılarak, $R_{i l k}$ ve $R_{\text {son }}$ hidrometre okumalarına göre etkin derinlik değeri, ardından da birim okuma için etkin derinlik değişimi belirlenebilmektedir. Bir hidrometre tipi için bilinen ilk ve son $L_{l}$ ve $R$ okumalarına göre birim okumada etkin derinlik değişimi Eşitlik 5'te verilmektedir.

$$
\Delta L=\frac{L_{\text {son }}-L_{i l k}}{R_{\text {son }}-R_{i l k}}
$$

$\mathrm{Bu}$ eşitliğe göre:

$\Delta L=$ birim hidrometre okumasında yaşanan etkin derinlik değişimi, $\mathrm{cm}$

$L_{i l k}=$ ilk hidrometre okumasında hesaplanan etkin derinlik, $\mathrm{cm}$

$L_{\text {son }}=$ son hidrometre okumasinda hesaplanan etkin derinlik, $\mathrm{cm}$

$R_{i l k}=$ ilk yapılan hidrometre okuması

$R_{\text {son }}=$ son yapilan hidrometre okuması olarak ifade edilmektedir.

Hidrometre okumasına bağlı etkin derinlik değerleri için; öncelikle Çizelge 2'de yer alan $L_{1}$ okuma değerlerinin Eşitlik 4 içerisinde yerine konmasıyla $151 \mathrm{H}$ ve $152 \mathrm{H}$ tipi hidrometreler için $L_{i l k}$ ve $L_{\text {son }}$ değerleri bulunması; ardından Eşitlik 5 'te yer alan birim okumada görülen etkin derinlik değişimi değeri olan $\Delta L$ 'nin bulunması gerekmektedir (Eşitlik 6).

$$
L=L_{i l k}-(\Delta L * R)+5.795
$$

Buna göre, ilk ve son hidrometre okumasındaki etkin derinlik $\left(L_{1}\right.$ ilk ve $L_{1}$ son) değerleri bilinen bir hidrometre için; bir hidrometre okumasına ait $(R)$ aranan etkin derinlik değeri $(L), \Delta L$ değerine bağl1 olarak Eşitlik 6'ya göre hesaplanabilmektedir. ASTM D422-63 [6] standart esasinda, $151 \mathrm{H}$ ve $152 \mathrm{H}$ tipi hidrometreler için; değişen hidrometre okumalarına göre etkin derinlik değerleri, çizelgeler haline getirilerek verilmiştir. Hidrometre deneyinin sonuçlandırılmasında son aşama olan toplam geçen yüzde oranlarının saptanması Eşitlik 7'de sunulmuştur.

$$
\% P=\frac{G_{s}}{M x\left(G_{s}-1\right)} \times 1000 \times P_{200} \times(R h-1)
$$

$\mathrm{Bu}$ eşitliğe göre:

$\% P=$ geçen yüzde, $(\%)$

$G_{s}=$ zemin örneğine ait özgül ağırlık

$M=$ zemin örneğinin kuru ağırlığı, $\mathrm{g}$

$R_{h}=$ düzeltme uygulanmış hidrometre okuması

$P_{200}=$ No.200 elekten toplam geçen yüzde, $(\%)$ [elek analizi deneyinden temin edilir] olarak ifade edilmektedir.

Bu matematiksel hesaplamalar her bir hidrometre okuması için adım adım gerçekleştirilir ve işlemler neticesinde her hidrometre okumasına karşılık geçen yüzde değerleri hesaplanır. Hidrometre deneyi için gereken deneysel veriler elde edildikten sonra, hidrometre deney sonuçları i) asıl hidrometre okumalarının düzeltilmesi, ii) dane çaplarının hesaplanması, iii) toplam geçen 
malzeme yüzdelerinin hesaplanması adımları takip edilerek çözümlenir.

\section{Yöntem}

Hidrometre deneyinin bilgisayar ortamında kodlanmasında ve açık kaynak yazılım geliştirme araçlarının seçilmesinde, öncül etken olarak kullanıcı ile erişebilirliğin arttırılması amacı gözetilmiştir. Yazılım geliştirmede; bilgisayar ve akıllı cihazların işletim sistemlerinden bağımsız bir şekilde erişebilirlik için çapraz platform teknolojilerinin ve internet tabanlı geliştirme araçlarının kullanımı büyük kolaylık sağlamaktadır. Özellikle modern yazılım dillerinin ve buna bağlı geliştirme araçlarının kullanımı; tekilliğe bağımlılığı azaltmak amacıyla, açık kaynak biçimde tasarım ve yönetime son derece uygundur [9]. Bu çalışmada, uygulama geliştirme platformu olarak ASP.NET Core [10], sayisal hesaplama kütüphanesi olarak Math.NET [11], basamaklı biçem şablonu olarak W3.CSS [12], taşınabilir belge biçiminde çıktı sunma amacıyla jsPDF [13] açık kaynak yazılım geliştirme araçları kullanılmıştır. ASP.NET Core platformu, 2016 yılında Microsoft .NET teknolojisinin oluşturduğu web altyapısında önemli bir ürün olarak ortaya sürülmüştür [14]. Burada kullanılan tüm uygulama geliştirme araçlarında, mantıksal ve yöntemsel işlemlerde $\mathrm{C \#}$ nesne yönelimli yazılım dili, görsel uygulama tasarımında HTML ve JavaScript işaretleme dilleri; sanal ortamdaki öge kodlamalarında kullanılmıştır (Şekil 3).

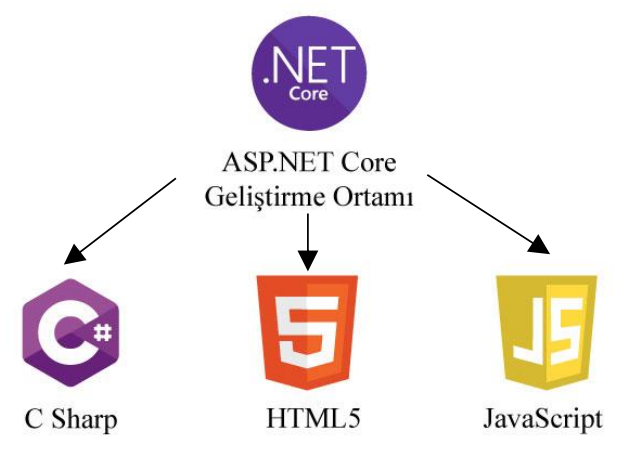

Şekil Hata! Belgede belirtilen stilde metne rastlanmadı.. Kullanılan açık kaynak yazılım geliştirme ortamı ile yazılım dilleri
Zemin örneği fiziksel bilgileri ile hidrometre ortamına ve donanımına özgü bilgiler; yazılım içerisinde Eşitlik 2'de yer alan $L$ ve $K$ değerlerini hesaplayabilmek için kullanılmaktadır. Eşitlik 2'de $L$ ve $K$ değerleri hesaplandıktan sonra $T$ değerine karşılık; Kod 1'de verilen yanıt döndüren yöntem kullanılarak yazılımda çözümlemeler tamamlanmaktadır.

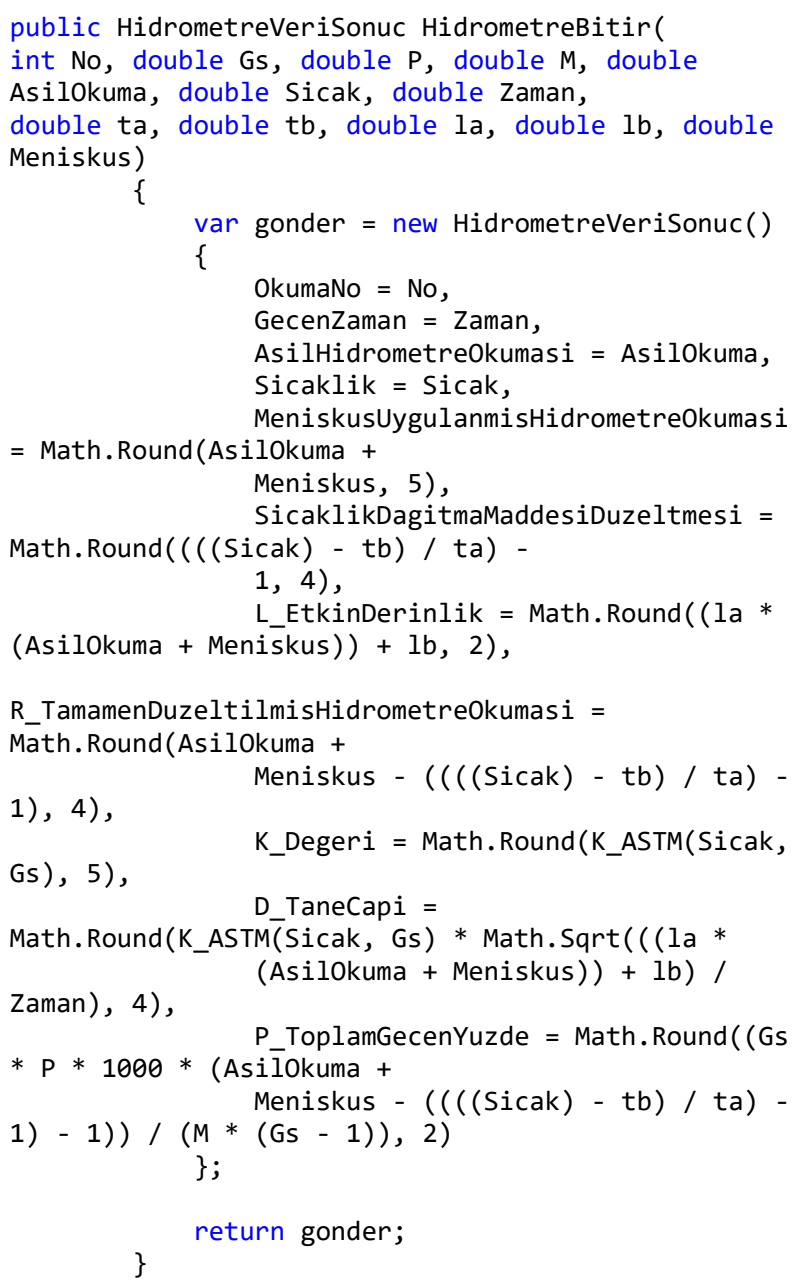

Kod 1. Hidrometre deneyi nihai çözümleme aşamasında veri döndüren kod metodu

Yazılımdaki hidrometre deneyi arayüzünde, kullanıcıdan; deneyde kullanılan zemin örneğinin fiziksel özellikleri, hidrometre tipi, dağıtma maddesi bilgisi, okuma düzeltmeleri, etkin derinlik sınır şartları, sıcaklık gibi nicel girdiler çeşitli deney adımlarında talep edilmektedir (Çizelge 3). 
Çizelge Hata! Belgede belirtilen stilde metne rastlanmadı.. Yazılım içerisinde kullanıcıdan talep edilen girdi veriler

\section{Kullanıcıdan Deneye Özgü Talep Edilen Veriler}

Zemin örneği özgül ağırlığı

Hidrometre tipi

No.200 elekten geçen toplam yüzde değeri

Dağıtma maddesi örneği (isteğe bağlı)
Kuru zemin örneği ağırlığ1

Menüsküs düzeltme katsayısı (varsayılan)

Hidrometre ölçüleri (isteğe bağl1)

Etkin derinlik okumaları (isteğe bağlı)

\section{Kullanıcıdan Deney Okuma Sayısına Göre Talep Edilen Veriler}

Assl hidrometre okumas1

Hidrometre deneyindeki matematiksel hesaplama adımları; nesne yönelimli yazılım dilleriyle, bir akış yolu işleyişi içerisinde, kullanıcı denetimli veri döndüren metotlara çevrilmiştir (Şekil 4).

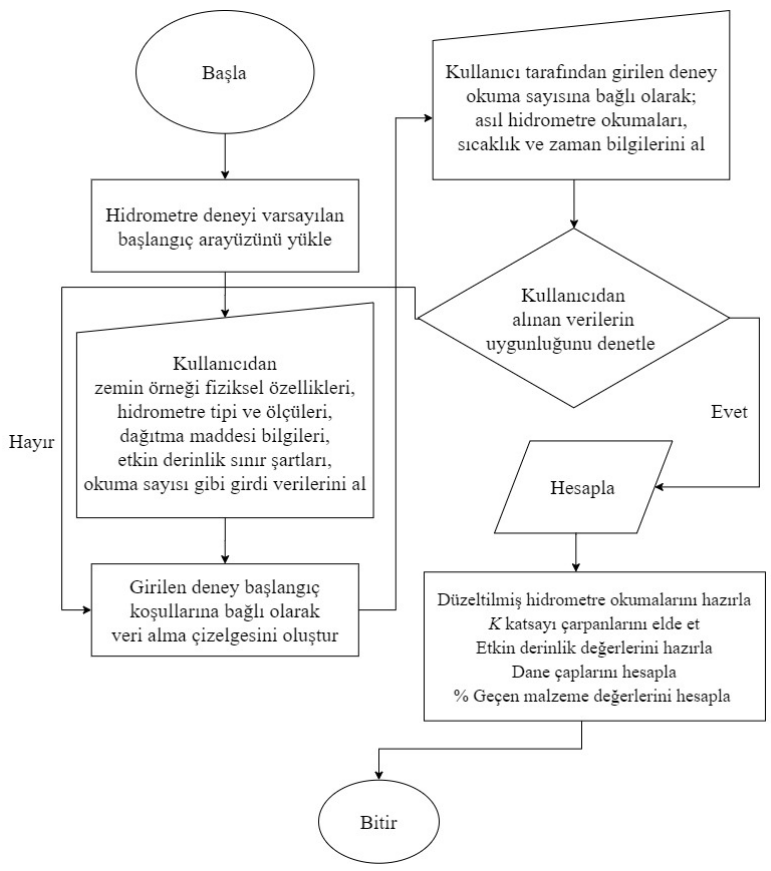

Şekil 4. Geliştirilen internet tabanlı uygulamanın akış yolu işleyişi

Şekil 4'te gösterilen akış yolu işleyişine göre; son kullanıcı tarafindan, deney başlangıcında girilen etkin derinlik okumaları ile özel hidrometre ölçülerine göre ya da yazılımda yer alan uluslararası standart hidrometre tip özelliklerine göre sunulmuş; etkin derinlik-okuma çizelgesi ile sicaklık-okuma doğrusu yer almaktadır. Son kullanıcının, deney okuma sayısına göre talep edilen asıl hidrometre okuması, zaman ve sıcaklık değerlerini girmesiyle birlikte derlenen tüm veriler, yazılım arayüzünde hesap sonuç aşamasında çözümlenir. Çözümleme sonucu, sıcaklık-dağıtma maddesi ve menüsküs düzeltme değerleri, düzeltilmiş hidrometre okumaları, dane çapları, $K$ katsayı değerleri ve toplam geçen malzeme yüzde değerleri; bir veri sonuç çizelgesi içerisinde kullanıcıya sunulmaktadır.

\section{Tasarım ve Bulgular}

Yapısal ve görsel mimarinin tamamlanmasıyla, yazılımdaki denetleme ve paketleme aşamaları; yine açık kaynaklı olarak paylaşılan Visual Studio Code derleyicisi üzerinden sürdürülmüştür. Tüm tasarım adımlarının sonucunda, tamamen açık kaynak yazılım gereçleriyle geliştirilen nihai uygulama; derleyiciden bağımsız olarak örnek bir tarayıcı üzerinden çalıştırılmıştır. Buna göre; hidrometre deneyi için hidrometre donanım ölçülerine ve deney yapılan zemin örneğine ait öncül bilgilerin alındığı yazılım başlangıç arayüzü EK A'da sunulmuştur. Başlangıç bölümünde girilen öncül verilere göre; sıcaklık düzeltmesinde kullanılmak üzere çizilen sıcaklık-okuma en iyi (optimum) doğrusu ile girilen okuma sayısına göre okumasıcaklık-süre veri alma çizelgesini içeren yazılım veri alma arayüzü EK B'de verilmiştir. Son olarak, tüm deney ortamı bilgilerine ve veri alma çizelgesinde işlenen girdilere göre; yazılımda gerçekleştirilen çözümleme sonuçları ile ince malzemenin dane çapı dağılımı eğrisi EK C'de yer almaktadır. Çizelge 4 ve Çizelge 5 'te yazılım 
Çizelge Hata! Belgede belirtilen stilde metne rastlanmadı.. Yazılım ile bilimsel yazınlar arasında gerçekleştirilen doğrulama sonuçları

\begin{tabular}{|c|c|c|c|c|c|c|c|c|c|c|c|}
\hline \multicolumn{3}{|c|}{$\begin{array}{c}\text { Doğrulama (I) } \\
\text { P, Geçen Yüzde (\%) }\end{array}$} & \multicolumn{3}{|c|}{$\begin{array}{c}\text { Doğrulama (II) } \\
\text { P, Geçen Yüzde (\%) } \\
\end{array}$} & \multicolumn{3}{|c|}{$\begin{array}{c}\text { Doğrulama (I) } \\
\text { D, Dane Çapı (mm) }\end{array}$} & \multicolumn{3}{|c|}{$\begin{array}{c}\text { Doğrulama (II) } \\
\text { D, Dane Çapı (mm) }\end{array}$} \\
\hline Yazılım & $\begin{array}{c}\text { Orhan } \\
\text { vd., [4] }\end{array}$ & $\begin{array}{l}\text { Fark } \\
(\%)\end{array}$ & Yazılım & $\begin{array}{c}\text { Yılmaz } \\
\text { vd., } \\
\text { [15] }\end{array}$ & $\begin{array}{l}\text { Fark } \\
(\%)\end{array}$ & Yazılım & $\begin{array}{l}\text { Orhan } \\
\text { vd., [4] }\end{array}$ & $\begin{array}{c}\text { Fark } \\
(\%)\end{array}$ & Yazılım & $\begin{array}{c}\text { Yılmaz } \\
\text { vd., } \\
\text { [15] }\end{array}$ & Fark (\%) \\
\hline 65.04 & 64.96 & 0.12 & 80.27 & 80.60 & 0.41 & 0.0395 & 0.0398 & 0.75 & 0.0583 & 0.0582 & 0.17 \\
\hline 62.03 & 61.95 & 0.13 & 77.03 & 77.35 & 0.41 & 0.0283 & 0.0285 & 0.70 & 0.0418 & 0.0419 & 0.24 \\
\hline 58.75 & 58.64 & 0.19 & 73.77 & 74.10 & 0.45 & 0.0183 & 0.0184 & 0.54 & 0.0300 & 0.0301 & 0.33 \\
\hline 56.34 & 56.24 & 0.18 & 72.15 & 72.48 & 0.46 & 0.0130 & 0.0131 & 0.76 & 0.0247 & 0.0247 & 0.00 \\
\hline 53.98 & 53.83 & 0.28 & 70.53 & 70.85 & 0.45 & 0.0109 & 0.0109 & 0.00 & 0.0152 & 0.0152 & 0.00 \\
\hline 51.58 & 51.43 & 0.29 & 68.90 & 69.23 & 0.48 & 0.0078 & 0.0078 & 0.00 & 0.0112 & 0.0112 & 0.00 \\
\hline 46.21 & 46.31 & 0.22 & 65.65 & 65.98 & 0.50 & 0.0057 & 0.0057 & 0.00 & 0.0080 & 0.0080 & 0.00 \\
\hline 41.78 & 41.80 & 0.05 & 63.05 & 63.38 & 0.52 & 0.0041 & 0.0042 & 2.38 & 0.0057 & 0.0057 & 0.00 \\
\hline 37.87 & 37.89 & 0.05 & 59.80 & 60.13 & 0.55 & 0.0028 & 0.0029 & 3.45 & 0.0041 & 0.0041 & 0.00 \\
\hline 33.63 & 33.68 & 0.15 & 55.57 & 55.90 & 0.59 & 0.0019 & 0.0019 & 0.00 & 0.0029 & 0.0029 & 0.00 \\
\hline 30.02 & 30.07 & 0.17 & 52.33 & 52.65 & 0.61 & 0.0012 & 0.0012 & 0.00 & 0.0021 & 0.0021 & 0.00 \\
\hline
\end{tabular}

Çizelge 5. Yazılımdan elde edilen deney çözüm sonuçlarının istatistiksel değerlendirmesi

\begin{tabular}{|c|c|c|c|c|c|}
\hline \multirow[b]{2}{*}{ Açıklama } & \multirow[b]{2}{*}{$\begin{array}{c}\text { Hata } \\
\text { Oranı }\end{array}$} & \multicolumn{2}{|c|}{ Doğrulama (I) } & \multicolumn{2}{|c|}{ Doğrulama (II) } \\
\hline & & $\begin{array}{l}\text { P, Geçen } \\
\text { Yüzde (\%) } \\
\text { Değeri için } \\
\text { Sonuçlar }\end{array}$ & $\begin{array}{c}\text { D, Dane Çapı } \\
\text { (mm) } \\
\text { Değeri için } \\
\text { Sonuçlar }\end{array}$ & $\begin{array}{c}\text { P, Geçen } \\
\text { Yüzde (\%) } \\
\text { Değeri için } \\
\text { Sonuçlar }\end{array}$ & $\begin{array}{c}\text { D, Dane Çapı } \\
\text { (mm) } \\
\text { Değeri için } \\
\text { Sonuçlar }\end{array}$ \\
\hline Ortalama Mutlak Hata & MAE & 0.08273 & 0.00008 & 0.32750 & 0.00002 \\
\hline Ortalama Karesel Hata & MSE & 0.00870 & 0.00000 & 0.10727 & 0.00000 \\
\hline Kök Ortalama Karesel Hata & RMSE & 0.09327 & 0.00012 & 0.32753 & 0.00005 \\
\hline $\begin{array}{c}\text { Ortalama Mutlak Yüzde } \\
\text { Hata }\end{array}$ & MAPE & 0.16539 & 0.78105 & 0.51124 & 0.06189 \\
\hline Açıklayıcılık Katsayısı & $\mathrm{R}^{2}$ & 0.999974 & 0.999984 & 1.000000 & 0.999992 \\
\hline
\end{tabular}

çözümleme sonuçları; literatürden seçilen birtakım deney verileri ile doğrulama yapmak amaciyla test edilmiştir. Seçilen bilimsel yazınlarda, ortaya konulan deney sonuç bulguları ile geliştirilen uygulamada, aynı verilerin çözümleme sonuçları, nicel olarak kıyaslanmıștır. İstatistiksel veri kıyaslamasında, literatürde yer alan ve hata-yakınsama ölçümlerinde kullanılan $\mathrm{R}^{2}$, MAE, MSE, RMSE, MAPE nicel değerlendirme ölçütleri tercih edilmiştir [16], [17]. Bu kiyaslama neticesinde elde edilen istatistiksel sonuçlara göre; açıklayıcılık katsayısının 0.99-1.00 arasında kalarak 1'e çok yakın olması, çeşitli istatistiksel hata ölçümleme değerlerinin ekseriyetle 0'a yakın olması nedeniyle yazılım çözümlemesinin başarılı olduğu görülmektedir. Yazılım çözümlemesi ile literatürde yer alan deney sonuçları arasındaki nicel tutarlılığın oldukça yakın olduğu tespit edilmiştir.

\section{Sonuçlar}

$\mathrm{Bu}$ çalışmada, hidrometre deneyi için; açık kaynak yazılım geliştirme araçlarıyla kodlanmış kullanıcı etkileşimli ve internet tabanlı bir uygulama oluşturulmuştur. $\mathrm{Bu}$ uygulama sonucunda elde edilen kazanımlar ve sonuçlar aşağıdaki gibi sıralanmıştır:

- Yazılım akış yolu içerisinde deney standartlarına bağlı olarak; deney veri sonuç çizelgesini, deney şartlarına göre düzeltmiş 
hidrometre okumaların1, hidrometre tipine ait etkin derinlik ve düzeltme katsayısı değerlerini, yarı logaritmik ölçekli dane çap1 dağılımı eğrisini; taşınabilir belge biçiminde çıktı olarak sunabilen bir uygulama elde edilmiştir.

- $\quad$ Yazılım girdi parametreleri olarak; zemin örneğinin fiziksel özellikleri, hidrometre tipi, dağıtma maddesi bilgisi, okuma düzeltmeleri, etkin derinlik sınır şartları gibi deneye ortamına özgü başlangıç koşul verileri ile deney tekrar sayısı kadar, asıl hidrometre okumasi-sicakl1kzaman deney verileri kullanılmaktadır.

- $\quad$ Literatürden yer alan bazı deney sonuçları ile yazılım çözümleme sonuçları; istatistiksel değerlendirme ölçütler yoluyla kıyaslandığında, açıklayıcılık katsayısının 1'e yakın, çeşitli istatistiksel hata ölçümleme değerlerinin ise 0'a yakın olduğu ve yazılım çözümleme performansının başarılı olduğu görülmektedir.

- Geliştirilen bu yazılımın kodlama, hesaplama, çıktı alma ve son kullanıcıya erişime sunulma adımlarının tamamı; açık kaynak geliştirme araçlarından seçilen bileşenler yoluyla tasarlanmıştır.

- $\quad$ Bu çalışma sonucunda, erişilebilirlik, özel amaçlı tasarım ve özgür lisanslama imkânı sağlayan açık kaynak yazılım geliştirme platformlarının, geoteknik mühendisliğinde içerisinde de kullanılabileceği görülmektedir. $\mathrm{Bu}$ tür çalışmalarla, geoteknik çözümlemelerde kullanılan ticari yazılımlara ve kapalı paket uygulamalara bir alternatif oluşacağı düșünülmektedir.

\section{Kaynaklar}

[1] Yılmaz, N. (2017). Açık Kaynak Yazılımlarda Bakım Yapılabilirliği ve Güvenilirliği Ölçmek İçin İki Boyutlu Değerlendirme Metodu, Yüksek Lisans Tezi, Hacettepe Üniversitesi, Temmuz 2017.

[2] Dipova, N. (2017). Açık Kaynaklı Geliştirme Platformlarının Geoteknik Laboratuvarı Çözümlerinde Kullanımı. Mehmet Akif Ersoy Üniversitesi Fen Bilimleri Enstitüsü Dergisi, 8 (2), 153-160.

[3] Eichhorn, G., Bowman, A., Haigh, S., Stanier, S. (2020). Low-cost digital image correlation and strain measurement for geotechnical applications. Strain. $10.1111 /$ str. 12348

[4] Orhan, M., Özer, M., Işık, S. N. (2004), “Zemin Mekaniği Laboratuvar Deneyleri Cilt I (İndeks ve Sınıflama Deneyleri)", Gazi Kitabevi.

[5] ASTM E100-15a (2015), Standard Specification for ASTM Hydrometers, ASTM International, West Conshohocken, PA, 2015, www.astm.org.

[6] ASTM D422-63 (2007), Standard Test Method for Particle-Size Analysis of Soils, ASTM International, West Conshohocken, PA, 2007, www.astm.org.

[7] S. Kakuturu, M. Xiao, and M. Kinzel, (2018), "Effects of Maximum Particle Size on the Results of Hydrometer Tests on Soils," Geotechnical Testing Journal 42, no. 4 2018: 945-965. https://doi.org/10.1520/GTJ20170236

[8] Das, B. M., Sobhan, K. (2017), "Principles of Geotechnical Engineering”, 9th Edition, Cengage Learning.

[9] Engel, P., Schweimler, B.. (2016), Development Of An Open-Source Automatic Deformation Monitoring System For Geodetical And Geotechnical Measurements. ISPRS - International Archives of the Photogrammetry, Remote Sensing and Spatial Information Sciences. XL-5/W8. 25-30.

[10] MathNet.Numerics (2020), github repository: mathnet / mathnet-numerics. Erişim: [18.06.2020]

[11] ASP.NET Core (2020), github repository: dotnet/aspnetcore. Erişim: [18.06.2020]

[12] W3.CSS (2020), W3.CSS Framework. W3Schools. Link: https://www.w3schools.com/w3css/default.asp Erişim: [18.06.2020]

[13] jsPDF (2020), github repository: MrRio/jsPDF. Erişim: [18.06.2020]

[14] Chiaretta, S. (2018), Front-end development with Asp.Net Core, Angular, and Bootstrap. Indianapolis, IN: John Wiley \& Sons, Inc.

[15] Yılmaz, I. \& Yıldırım, M. \& Keskin, İ. (2016), "Zemin Mekaniği Laboratuvar Deneyleri ve Çözümlü Problemler”, Seçkin Yayıncılık.

[16] Singh, P. \& Kumar, D. \& Samui, P. (2020). Reliability Analysis of Rock Slope Using Soft Computing Techniques. Jordan Journal of Civil Engineering, Volume 14, No. 1, 2020.

[17] Prayudani, S., Hizriadi, A., Lase, Y. Y., Fatmi, Y., \& Al-Khowarizmi. (2019). Analysis Accuracy Of Forecasting Measurement Technique On Random KNearest Neighbor (RKNN) Using MAPE And MSE. Journal of Physics: Conference Series, 1361, 012089. 


\section{EK A}

Hidrometre deneyi yazılım arayüzünde; deneye ait başlangıç koşullarının, donanım ölçülerinin ve yapılacak okuma sayısının girdi bölümleri

Zemin Örneği Fiziksel Özellikleri

Zemin Örneğinin Özgül Ağırlığı, Gs :

Zemin Kuru Örnek Ağırığı, M (g) :

No.200 Elekten Geçen Toplam Yüzde, P200 (\%) :

\begin{tabular}{|c|}
\hline 2.66 \\
\hline \hline 40 \\
\hline \hline 63 \\
\hline
\end{tabular}

Deney Aleti ve Çözelti Malzemesinin Belirlenmesi

Dağıtma Maddesi (Çözelti): $\quad 130 \mathrm{~mL} \mathrm{NaPO}$

Hidrometre Tipi:

ASTM $151 \mathrm{H}$

Menisküs Düzeltmesinin Belirlenmesi

Varsayılan Menisküs Düzeltme Değeri:

0.0008

Sıcaklık ve Dağıtma Maddesi Düzeltmesinin Belirlenmesi

Varsayılan Doğrusal Regresyon Determinasyon Katsayısı, R² : 0.99739



Not: Bu Okumalardan R² Belirlenmiştir ve Bir Düzeltme Regrasyon Doğrusu Oluşturulacaktır

Özel Bir Kalibrasyon Kullanmak için İşaretleyin Özel Bir Kalibrasyon Kullanmak için Okuma Sayısı Girin:

Etkin Derinliğin Belirlenmesi

Etkin Derinlik - Kullanılan Hidrometre Tipi :

ASTM $151 \mathrm{H}$

L2 :

A 27.8

Vb :

67

\begin{tabular}{|c|c|c|c|}
\hline Okuma : & 1 & $\mathrm{~L}_{1}:$ & 10.5 \\
\hline Okuma : & 1.031 & $\mathrm{~L}_{1}:$ & 2.3 \\
\hline
\end{tabular}

Hidrometre Deneyi Okuma Sayısının Belirlenmesi

Hidrometre Deneyi Okuma Sayısı :

1

Veri Alma Çizelgesini Oluştur 


\section{EK B}

Hidrometre deneyi yazılım arayüzünde, okuma sayısına göre oluşturulan veri alma çizelgesi örneği ile sıcaklık kaynaklı hidrometre okuma düzeltmesi için çizilen en iyi doğru (regresyon)

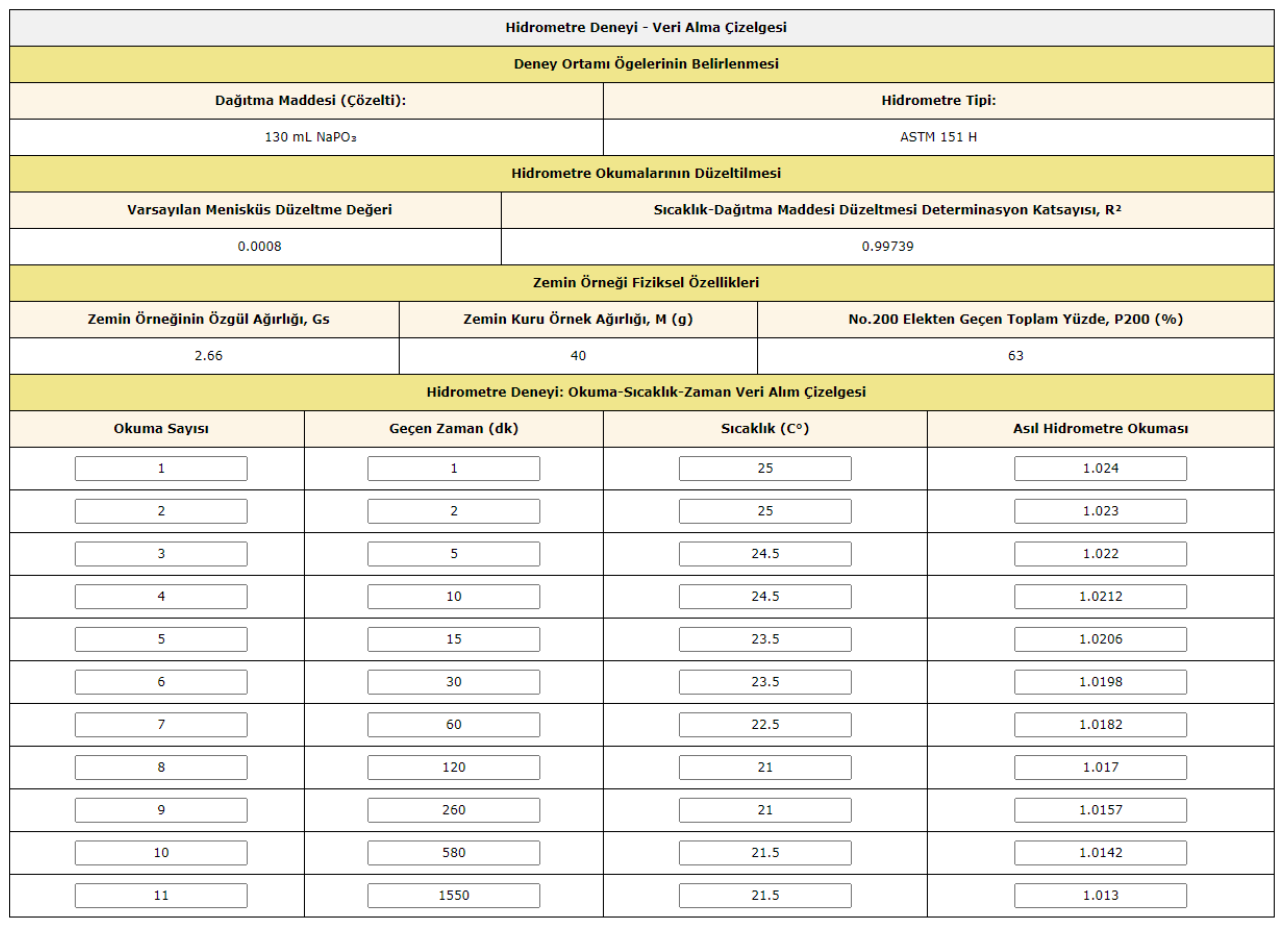

HESAPLA

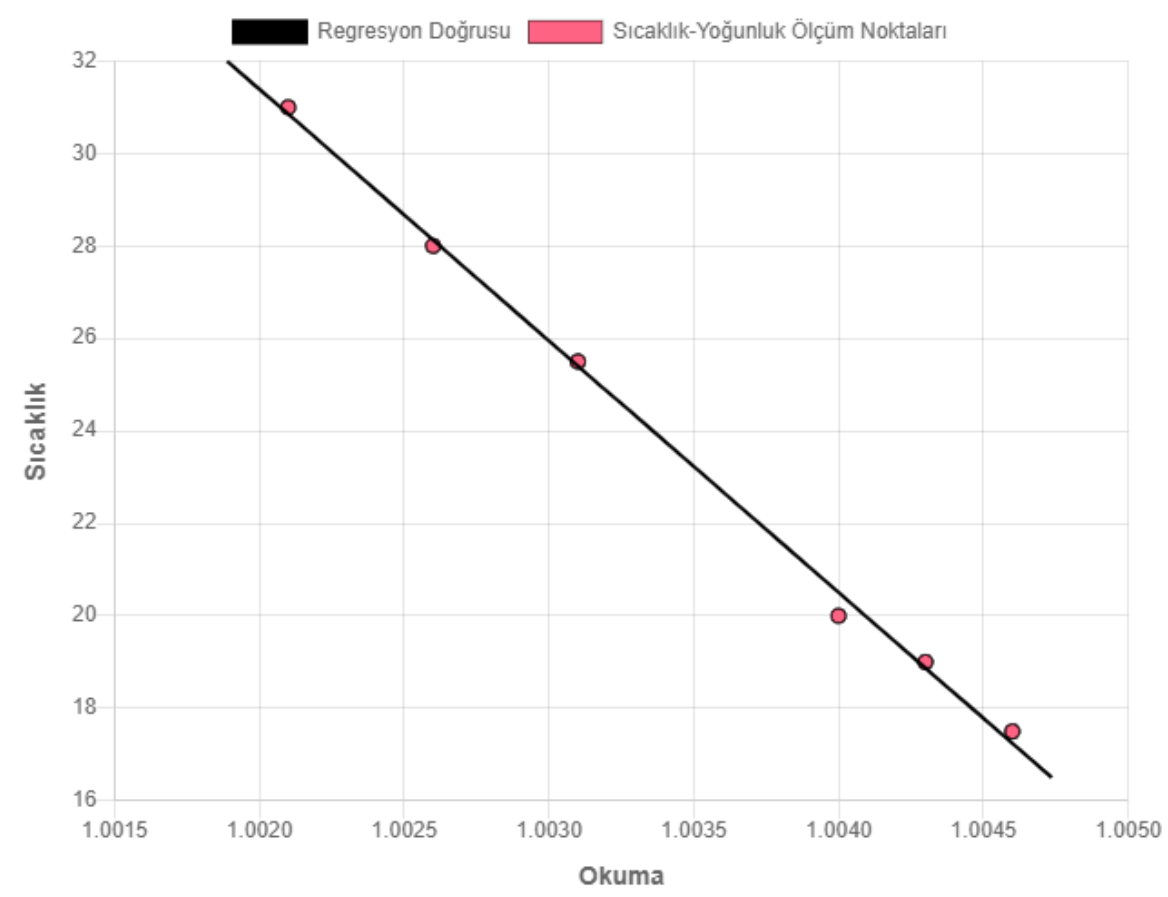




\section{EK C}

Yazılım içerisinde gerçekleşen çözümleme sonucu elde edilen hesap sonuç çizelgesi ile hidrometre deneyi dane çapı dağılımı eğrisi

\begin{tabular}{|c|c|c|c|c|c|c|c|c|c|c|}
\hline \multicolumn{11}{|c|}{ Hidrometre Deney Sonuçları } \\
\hline $\begin{array}{c}\text { Okuma } \\
\text { Sayısı }\end{array}$ & $\begin{array}{c}\text { Geçen } \\
\text { Zaman } \\
\text { (dk) }\end{array}$ & $\begin{array}{c}\text { Sicaklık } \\
\left(\mathrm{C}^{\circ}\right)\end{array}$ & $\begin{array}{c}\text { Asıl } \\
\text { Hidrometre } \\
\text { Okuması }\end{array}$ & $\begin{array}{l}\text { Menisküs } \\
\text { Düzeltmesi } \\
\text { Uygulanmış } \\
\text { Hidrometre } \\
\text { Okuması }\end{array}$ & $\begin{array}{l}\text { Sıcaklık- } \\
\text { Dağıtma } \\
\text { Maddesi } \\
\text { Düzeltmesi }\end{array}$ & $\begin{array}{c}\text { Düzeltmeleri } \\
\text { Tamamlanmış } \\
\text { Nihai } \\
\text { Hidrometre } \\
\text { Okumaları, Rh }\end{array}$ & $\begin{array}{c}\text { Etkin } \\
\text { Derinlik, } \\
\text { L (cm) }\end{array}$ & $\begin{array}{c}\mathbf{K} \\
\text { Değeri }\end{array}$ & $\begin{array}{c}\text { Dane } \\
\text { Çapı, } \\
\text { D } \\
(\mathrm{mm})\end{array}$ & $\begin{array}{l}\text { Toplam } \\
\text { Geçen, } \\
\text { P (\%) }\end{array}$ \\
\hline 1 & 1 & 25 & 1.024 & 1.0248 & 0.0032 & 1.0216 & 9.73 & 0.01282 & 0.04 & 54.58 \\
\hline 2 & 2 & 25 & 1.023 & 1.0238 & 0.0032 & 1.0206 & 10 & 0.01282 & 0.0287 & 52.05 \\
\hline 3 & 5 & 24.5 & 1.022 & 1.0228 & 0.0033 & 1.0195 & 10.26 & 0.0129 & 0.0185 & 49.3 \\
\hline 4 & 10 & 24.5 & 1.0212 & 1.022 & 0.0033 & 1.0187 & 10.48 & 0.0129 & 0.0132 & 47.28 \\
\hline 5 & 15 & 23.5 & 1.0206 & 1.0214 & 0.0034 & 1.018 & 10.63 & 0.01305 & 0.011 & 45.3 \\
\hline 6 & 30 & 23.5 & 1.0198 & 1.0206 & 0.0034 & 1.0172 & 10.85 & 0.01305 & 0.0078 & 43.28 \\
\hline 7 & 60 & 22.5 & 1.0182 & 1.019 & 0.0036 & 1.0154 & 11.27 & 0.0132 & 0.0057 & 38.78 \\
\hline 8 & 120 & 21 & 1.017 & 1.0178 & 0.0039 & 1.0139 & 11.59 & 0.01344 & 0.0042 & 35.06 \\
\hline 9 & 260 & 21 & 1.0157 & 1.0165 & 0.0039 & 1.0126 & 11.93 & 0.01344 & 0.0029 & 31.78 \\
\hline 10 & 580 & 21.5 & 1.0142 & 1.015 & 0.0038 & 1.0112 & 12.33 & 0.01336 & 0.0019 & 28.22 \\
\hline 11 & 1550 & 21.5 & 1.013 & 1.0138 & 0.0038 & 1.01 & 12.64 & 0.01336 & 0.0012 & 25.19 \\
\hline
\end{tabular}

Hidrometre Deneyi - Dane Çapı Dağııımı Eğrisi

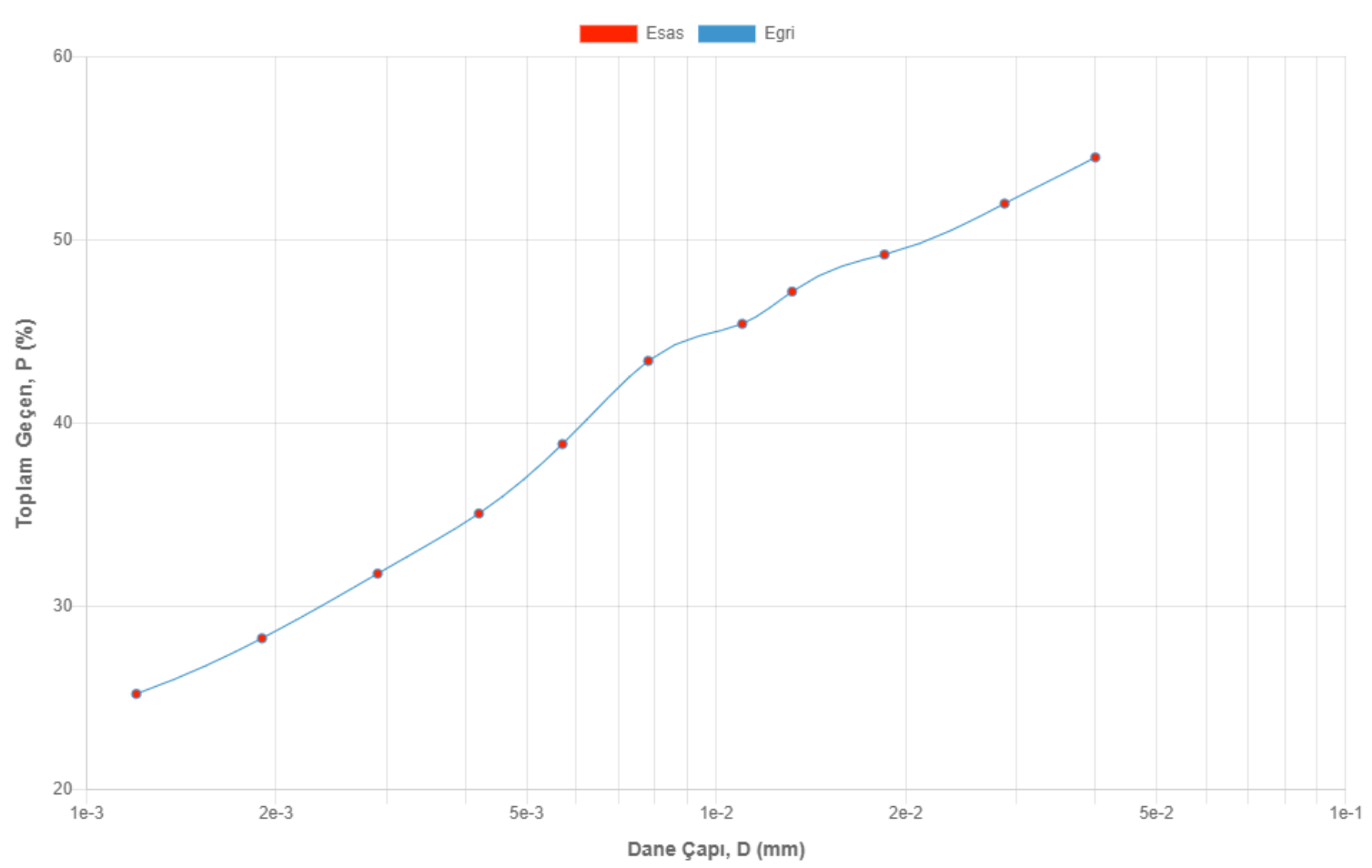

